[Aus dem Institut für Infektionskrankheiten „Robert Koeh“.]

(Direktor: Geh. Med.-Rat Prof. Dr. Ne ufeld.)

\title{
Beitrag zur Frage der Weil-Felixschen Reaktion und der Paragglutination.
}

Von

Dr. Papamarku,

Assistent am Institut.

Die nachstehenden Versuche bezweckten, gewölnliche Proteusstämme in vitro zu Weil-Felix-ähnlichen Stämmen umzuzüchten. Wenn es auch nur recht unvollkommen gelang, dieses Ziel zu erreichen, so dürften die Ergebnisse doch theoretisch von Interesse sein.

In enge Röhrchen (Präzipitationsröhrchen), die 0.3 bis $1 \mathrm{ccm}$ inaktives, mit etwas Bouillon verdünntes Fleckfieberkrankenserum B enthielten, wurde Proteus geimpft und darauf wieder täglich in ebensolche Röhrchen weiter geimpft. Ein Teil der Röhrchen wurde mit flüssigem Paraffin überschichtet. Nach verschiedenen Passagen wurden daraus Agarkulturen angelegt und mit demselben Serum B wie auch mit einem anderen Fleckfieberserum C agglutiniert. Die Resultate sind in der Tab. 1 wiedergegeben. Die Fähigkeit des Proteus, zu agglutinieren, versehwand nach drej Agarpassagen.

Tabelle 1.

Versuch I: Agglutination aus Agarkultur. Beobacbtung nach 2 Stunden bei $37^{\circ}$ mit der Lupe.

\begin{tabular}{c|c|c}
\hline S t a m m & $\begin{array}{c}\text { Serum B } \\
\text { Titer mit X 19 } \\
1: 800\end{array}$ & $\begin{array}{c}\text { Serum C } \\
\text { Titer mit X 19 } \\
1: 1000\end{array}$ \\
\hline Proteus 5. Passage in Serum B, aerob & $\begin{array}{l}1: 40+ \\
1: 40+\end{array}$ & $1: 40+$ \\
Proteus 5, Passage in Serum B, anaerob & $\begin{array}{l}1: 400 \pm \\
1: 25-\end{array}$ & $1: 40+$ \\
Proteusausgangskultur . . . . . . . & $1: 25-$
\end{tabular}


Im zweiten und dritten Versuch wurde, um einen etwaigen Rückgang der Agglutinabilität in der Agarkultur zu vermeiden, unmittelbar aus den Passagekulturen auf kleine Bouillonröhrchen weitergeimpft, denen das agglutinierende Serum in Verdünnung 1:25, 1:50 usw. zugesetzt war. Die Prüfung entsprach also der sogenannten Fadenreaktion. Das Ergebnis wurde nach 2stündigem Aufenthalte im Brutschrank im hängenden Tropfen festgestellt. Den Erfolg zeigen die Tabb. 2 und 3.

\section{Tabelle 2.}

Versuch II: Fadenreaktion, mikroskopisch im hängenden Tropfen nach 2 Stunden bei $37^{\circ}$ beobachtet.

\begin{tabular}{c|c}
\hline S t a m m & $\begin{array}{c}\text { Serum I. } \\
\text { Fleckfieberkrsnkenserum mit X 19 } \\
\text { Titer 1:1000+ }\end{array}$ \\
\hline Proteus 4. Passage im Serum I, anaerob & $1: 25+$ \\
Proteus 4. Passage im Serum II, anaerob & $1: 50+$ \\
$\begin{array}{c}\text { Serum II = Fleckfieberkrankenserum von } \\
\text { den ersten Tagen der Krankheit mit } \\
\text { X 19 1:100 negativ }\end{array}$ & $1: 100 \pm$ \\
Proteusausgangskultur . . . . . . . & $1: 200 \pm$ \\
\end{tabular}

Tabelle 3.

Versuch III: Beobachtung der Fadenreaktion wie in Versuch II.

\begin{tabular}{|c|c|c|}
\hline Stamm anaerob & $\begin{array}{c}\text { Fleckfieberkrankenserum } \\
\text { (Untersuchungsamt) } \\
\text { Titer } 1: 800\end{array}$ & $\begin{array}{c}\text { Agglutination } \\
\text { mit den } \\
\text { homologen Seris }\end{array}$ \\
\hline $\begin{array}{l}\text { 3. Passage in Ser. 1. (6. Krankheitg- } \\
\text { tag mit } X 191: 100 \text { negativ) }\end{array}$ & $\begin{array}{l}1: 25+ \\
1: 50 \pm\end{array}$ & Serum 1. $1: 75 \pm$ \\
\hline $\begin{array}{l}\text { 4. Passage in Ser. 2. (9. Krankheits- } \\
\text { tag mit X 19 1:800 positiv) }\end{array}$ & $\begin{array}{l}1: 25+ \\
1: 50 \pm\end{array}$ & Serum 2. $1: 25 \pm$ \\
\hline $\begin{array}{l}\text { 4. Passage in Ser. 3. (11. Krankheits- } \\
\text { tag mit X } 191: 200 \text { sehw. pos.) }\end{array}$ & $1: 25 \pm$ & Serum 3. $1: 25 \pm$ \\
\hline Proteusausgangskultur & $1: 25-$ & $\begin{array}{ccc}\text { Serum } & 1 . & 1: 25- \\
, & 2 . & 1: 25- \\
, & 3 . & 1: 25-\end{array}$ \\
\hline
\end{tabular}

Passageversuche in defibriniertem Blut anstatt in Serum von Fleckfieberkranken haben nur negative Resultate ergebon.

In den Tabellen sind nụr die Versuche mit denjenigen Passagen angeführt, die die höchsten Agglutinationswerte ergaben.

Hiernach ist es also mehrfach gelungen, einen gewöhnlichen Proteusstamm durch Züchtung im Serum von Fleckfieberkranken so zu verändern, daß er eine, wenn auch nicht starke, so doch zweifellos spezifische 
Agglutination mit Fleckfieberserum annahm. Die Veränderung trat stets nach wenigen Passagen ein, ließ sich aber durch weitere Passagen im selben Medium nicht mehr steigern; sie gelang auch durch Züchtung in Serum, das aus der ersten Zeit der Krankheit stammte und wenig oder gar kein Agglutinin für X 19 enthielt, und zwar in Versuch II besser als in einem stark agglutininhaltigen Serum aus späteren Krankheitstagen.

Die Veränderung wird also offenbar nicht durch Antikörper, sondern durch den Antigengehalt des Serums hervorgerufen. Dabei agglutinierten die veränderten Stämme bisweilen mit dem Serum, in dem sie gezüchtet waren, besser als mit anderen Fleckfiebersera. (Besonders deutlich in einem Versuch der Tabelle 1.)

Wie gesagt, sind die erzielten Agglutinationswerte nur gering, bekanntlich sind aber neben dem Bazillus X 19 aus Fleckfieberfällen vielfach Proteusstämme gezüchtet worden, die ebenfalls nur eine geringe Agglutinabilität für Fleckfieberseren aufweisen.

Unsere Befunde sprechen deutlich für die Auffassung der WeilFelixschen Reaktion als einer Paragglutination, besonders im Verein mit den Ergebnissen einiger Arbeiten, die während unserer Untersuchungen erschienen sind.

Oettinger ${ }^{1}$ gelang es, Proteusstämme durch mehrfache Züchtung in mit defibriniertem Blut von Fleckfieberkranken versetzten Bouillon- und Agarröhrchen (Stich- und Oberflächenkultur) so umzuwandeln, daß sie agglutinierten; die höchsten Werte waren 1:100 bis 1:200. Ferner zuichtete Oettinger aus Stuhl und Harn von Fleckfieberkranken 7 Coliund 2 Kokkenstämme und aus Blut einen Kokkus, die mäßig stark, aber spezifisch mit Fleckfieberserum agghutinierten; die Stämme verloren diese Eigenschaft größtenteils innerhalb 2 Monaten.

Kreuscher ${ }^{2}$ züchtete aus dem Stubl eines Fleckfieberkranken einen Pyocyanus, der mit 71 Prozent der untersuchten Fleckfieberseren bis 1: 50 agglutinierte, mit anderweitigen menschlichen Seris dagegen nur in 9 Prozent.

Schürmann hat aus Blut von Rekurrensfällen sowie aus Harn von Syphiliskranken Kokken gezuichtet, die mit Sera von Rekurrens- bzw. Syphilisfällen eine spezifische Agglutination, meist allerdings nur in der Verdünnung $1: 50$ bis $1: 100$, ergaben, die bei normalen Kontrollseris fehlte.

Die Gesamtheit dieser Befunde spricht meines Erachtens aufs deutlichste dafür, die Weil-Felixsche Reaktion als eine Paragglutination auf-

1 Oettinger, Zentralbl. f. Bakt. Bd. LXXX. S. 304.

2 Kre uscher, Berliner klin. Wochenschr. 1918. Nr. 16. S. 374.

3 Schürmann, Deutsche med. Wočhenschr. 1917. S. 464. 
zufassen. Die Oettinger und uns in vitro gelungene Umwandlung gewöhnlicher Proteusstämme in der Richtung einer spezifischen Agglutinabilität für Fleckfieberseren kaṇn doch nur als Parasglutination aufgefaßt werden, und ebensowenig scheint uns für die Agglutination der aus Fleckfieberfällen gezüchteten Coli-, Kokken- und Pyocoaneuskulturen und der aus Syphilis und Rekurrens gezüchteten Kokken eine andere Deutung möglich. Diese Stämme kommen weder als Erreger der betreffenden Krankheiten, noch als Mischinfektionserreger in Frage. Warum soll man gerade für die Weil-Felixschen Proteusstämme etwas anderes annehmen?

Die Unterschiede sind doch nicht grundsätzliche, sondern nur graduelle, und auch die vielen beim Fleckfieber gezüchteten Proteusstämme zeigen untereinander ạlle Abstufungen bezüglich der Höhe der Agglutinabilität.

Gerade bei typischer Paragglutination ${ }^{1}$ sind aber sehr weitgehende Unterschiede bezüglich der Stärke und Dauer der Agglutinationsfähigkeit schon von den Entdeckern der Paragglutination beschrieben worden.

Kuhn, Woithe und Gildemeister fanden im Darminhalt chronisch Ruhrkranker Colistämme, die mit einem Flexner-Kaninchenserum bis zur Titergrenze $1: 20000$, und daneben solche, die nur bis $1: 100$ Paragglutination zeigten. Einzelne Stämme behielten die Eigenschaft 5 Monate lang in gleicher Höhe, bei anderen ging sie in 4 Tagen schon merklich zurück.

Auch Ornsteins, der aus Stuhl und Blut nicht nur paragglutinierende Coli-, sondern auch zahlreiche Typhusstämme züchtete, die mit Flexnerserum Paragglutination zeigten, fand alle Abstufungen bezüglich der Titerhöhe und der Haltbarkeit der Paragglutination; in einem Falle war sie noch nach 16 Monaten vollständig erhalten. Giesczczykiewiz‘ fand bei Untersuchung zahlreicher paragglutinierender Colistämme die Agglutinabilität für Flexnerserum nach 1 Jahr meist erhalten oder wenig verringert, während die gleichzeitig bei denselben Stämmen vorhandene Agglutinabilität für Typhusserum in der Mehrzahl der Fälle erheblich (auf $1 / 3$ bis $1 / 8$ ) sank, in einigen Fällen vollständig verloren ging. Ditthorn und Neumarks

1 Es ist nötig, die zahlreichen Mitteilungen über Paragglutination kritisch zu sichten. Zu den von Messerschmid u. a. beschriebenen Beobachtungen über choleraparagglutinierende Colistämme se bemerkt, daß nach den sehr zahlreichen Beobachtungen, die Dr. Schiemann in unserem Institut darüber gemacht hat, solche Stämme in choleraverdächtiger Fäzes zum mindesten äußerst selten sind. Dagegen kommt es öfter vor, daß gewisse Pferdesera, insbesondere aber Sera von Pferden, die lange immunisiert worden sind, Colistämme hoch agglutinieren. Auch wir haben das an unseren alten Cholerapferdeseris oft beobachtet und geben deswegen zu diagnostischen Zwecken in der Regel Kaninchensera ab.

2 Arbeiten aus dem Kais. Gesundheitsamt. XXXI. S. 394.

3 Ornstein, Diese Z̈eitschrift. Bd. LXXXV. 8. 374.

t Giesczczykie wi z, Zentralbl. f. Bakt. Bd. LXXVII. S. 104 .

-Ditthorn und Neumark, Zentralbl. $f$. Bakt. 1913. Orig.-Bd. LXVII. 
fanden bei einem mit Typhusserum paragglutinierenden Colistamm die Agglutinabilität nach 3 Jahren noch ebenso stark wie anfangs.

Es bedeutet also keinen grundsätzlichen Unterschied, wenn sie bei den Weil-Felixstämmen mehrere Jahre unverändert geblieben ist. Auch die anderweitig erworbenen Veränderungen von Bakterien lassen sich nicht einfach als bleibende und vorübergehende unterscheiden, sondern wir sehen dazwischen alle möglichen tbbergänge (vgl. dazu die Ausführungen von Bernhardt').

Die Tatsache, daß die Agglutinabilität der künstlich veränderten Proteusstämme weit unter derjenigen der X 19 Proteus bleibt, kann, abgesehen von den vielfachen Befunden schwach agglutinierender Stämme, wie X 2, bei Fleckfieberfällen schon deswegen nicht gegen die Auffassung des letzteren als eines paragglutinierenden Stammes angeführt werden, weil die Versuche, Colistämme künstlich zu einer Paragglutination mit Ruhr- oder anderen Sera heranzuzüchten, bisher ebenfalls nur sehr unvollkommene und unregelmäßige Ergebnisse gehabt haben. Kuhn und Ebeling² haben durch Züchtung von Colibazillen in Bouillon und Agar, in welchem vorher Flexner gewachsen war, zwar zweimal einen Agglutinationstiter von 1:10000 erreicht, in den meisten ihrer zahlreichen Versuche trat aber gar keine oder nur sehr geringe Paragglutination ein. Lentz ${ }^{3}$ teilt mit, daß es Keysser gelungen ist, Colistämmen dadurch eine hohe Paragglutinabilität für Flexnerserum anzuzüchten, daß er sie längere Zeit in Extrakten oder bakterienfrei gemachten alten Bouillonkulturen von Flexnerbazillen wachsen ließ. Die Versuche sind nicht näher veröffentlicht worden.

Es ist sebr bedauerlich, daß bisher kein Verfahren bekannt ist, um mit einer gewissen Sicherheit in vitro stark paragglutinierende Bakterien heranzuzüchten; denn dann wäre es eine lohnende Aufgabe, zu versuchen, derartige Stämme durch Züchtung in antigenhaltigen Medien, wie Blutserum oder Organextrakten, zu gewinnen und zur Diagnose von Infektionskrankheiten zu benutzen, bei denen wir bisher kein spezifisches Verfahren zur Diagnose besitzen. Ausgehend von diesem naheliegenden Gedanken, der bereits von anderen Autoren ausgesprochen worden ist (Oettinger), haben wir uns bemüht, zunächst Colistämmen eine stärkere Paragglutination für Typhus oder Ruhr anzuzüchten. AliBer der Züchtung in Bouillon-

1 Bernhardt, Diese Zeitschrift. Bd. LXXIX. S. 179.

2 Kuhn und Ebeling, Zeitschr. f. Immunitätsforschung. Bd. XXV. Nr. 1.

a Lentz, Dysenterie. Kolle-Wassermanns Handbuch der pathogenen Mikroorganismen. Bd. III. S. 951 . 
mischkulturen und Kochsalzextrakten versuchten wir: anaerobe und aerobe Züchtung in Fäzes und Galle, worin vorher die betreffenden spezifischen Bakterien gewachsen waren bzw. gleichzeitig wuchsen, Züchtung in äußerst nährstoffarmen Medien mit Zusatz der betreffenden Extrakte (um die Colibazillen durch Nahrungsmangel zur Assimilierung der fremden Bakterienstoffe zu zwingen), wir verwendeten statt der gewöhnlichen Extrakte Typhusbazillen, die durch Komplement aufgelöst waren, wir injizierten 1 Öse Colibazillen in die Bauchhöhle von Meerschweinchen, in die einige Stunden vorher $1 / 2$ Kultur Y-Ruhrbazillen allein oder znsammen mit spezifischem. Serum eingespritzt und größtenteils aufgelöst worden war, und züchteten nach verschiedenen Zeiten die Colibazillen wieder heraus. Alle diese Versuche sind aber unbefriedigend verlaufen; wir haben niemals mehr als eine geringe und vorübergehende Agglutinabilität erreichen können.

Besonders aussichtsvoll erschien uns aber folgender Weg: Es ist bekannt, daß man bei Versuchen über die Variabilität von Bakterien vielfach Stämme abspalten konnte, die - zum Teil neben morphologischen und kulturellen Veränderungen, zum Teil ohne solehe - die verschiedensten Abweichungen bezüglich der Agglutination zeigten. So konnte Bernhardt' aus alten Typhuskulturen Stämme gewinnen, die teils schwach, teils gar nicht mit Typhusserum, zum Teil auch nicht mit ihrem Eigenserum agglutinierten, wobei sich wieder solche unterscheiden ließen, die noch agglutinogen wirkten, und andere, bei denen auch das nicht mehr der Fall war; besonders merkwürdig waren Stämme, die nur mit Serum, das mit einer bestimmten Typhusvariante hergestellt war, agglutinierten, dagegen mit keinem der sonst benutzten Typhussera. Bekanntlich hat neuerdings Felix beobachtet, daß auch die X-19-Bazillen sich in zwei verschiedene Varianten spalten lassen, die agglutinatorisch und zugleich kulturell verschieden sind.

Nun hat man bisher bei denı Versuch, paragglutinierende Stämme künstlich zu erzeugen, sich wohl allgemein damit begnügt, zu untersuchen, ob die ganze Kultur agglutinabel geworden war. Nach dem Gesagten schien es uns aber aussichtsreich, zu sehen, ob nicht wenigstens einzelne Kolonien abgespalten werden, die agglutinatorisch verändert sind. Natürlich sind solche Untersuchungen recht mühsam; schon Bernhardt hat lemerkt, daß, wenn es ebenso leicht wäre, beispielsweise eine agglutinatorisch veränderte Typhuskolonie unter 100 anderen herauszufinden wie eine im Wachstum abweichende, man solche agglutinatorischen Verände-

1 Diese Zeitschrift. Bd. LXXIX. S. 219-223. 
rungen wohl viel häufiger finden würde. Bei unseren Untersuchingen hat sich nun noch eine andere Schwierigkeit ergeben: es spalteten sich von unseren Colistämmen oft spontan Varianten ab, die schon mit Normalseris ziemlich hoch agglutinierten. Angesichts dieser Schwierigkeiten möchten wir die negativen Ergebnisse, die wir bei einigen Versuchen dieser Art sowohl mit Proteus- wie mit Colistämmen bisher hatten, noch nicht für entscheidend halten. 